\title{
Estradiol/Norethindrone Acetate Tablet
}

National Cancer Institute

\section{Source}

National Cancer Institute. Estradio//Norethindrone Acetate Tablet. NCI Thesaurus. Code C84875.

An orally bioavailable tablet formulation containing the semisynthetic estrogen estradiol in combination with the acetate form of the synthetic progestin norethindrone, with estrogenic and progesteronic activities. Estradiol binds to and activates intracellular estrogen receptors found in the reproductive tract and other estrogen-responsive tissues. The activated complex enters the nucleus, binds to the estrogen response elements on DNA, and activates the transcription of genes involved in the maintenance of the female reproductive system and secondary sexual characteristics, the proliferation of the endometrium, and bone metabolism. Norethindrone binds to the intracellular progesterone receptors in the reproductive system and the activated ligand/receptor complex interacts with specific DNA response elements, resulting in an alteration in protein synthesis; inhibition of luteinizing hormone (LH) and follicle stimulating hormone (FSH) release; inhibition of ovulation; an increase in cervical mucus production; and induction of the secretory phase of the endometrial cycle. Administration of estradiol/norethindrone acetate may abrogate vasomotor symptoms associated with menopause and prevent bone loss associated with the postmenopause. Because chronic estrogen stimulation unopposed by progesterone may increase the risk of the endometrial carcinoma, administration of a combination estrogen-progestin in postmenopause may reduce the risk for women who require estrogen replacement therapy. 